\title{
Fabry's disease with complete atrioventricular block: histological evidence of involvement of the conduction system
}

Yuji Ikari, Kenji Kuwako, Tetsu Yamaguchi

\begin{abstract}
A 63 year old man with complete atrioventricular block was diagnosed as having Fabry's disease. A short PR interval is a common electrocardiographic finding in Fabry's disease, but complete atrioventricular block is a very rare complication. Necropsy indicated that lipid accumulation in the atrioventricular conduction system was the probable cause of this patient's atrioventricular block.
\end{abstract}

(Br Heart J 1992;68:323-5)

Fabry's disease is an inherited disorder that causes glycosphingolipids to accumulate because of a deficiency of $\alpha$-galactosidase A. ${ }^{1}$ Cardiac involvement associated with left ventricular enlargement and supraventricular arrhythmias is quite common. ${ }^{2-4} \mathrm{~A}$ short $\mathrm{PR}$

\section{Division of}

Cardiology, Mitsui

Memorial Hospital 1, Tokyo, Japan

Y Ikari

K Kuwako

T Yamaguchi

Correspondence to Dr Yuji Ikari, Mitsui Memorial Hospital, 1, Kandaizumi-cho,

Chiyoda-ku, Tokyo 101,

Japan.

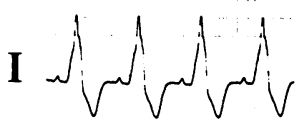

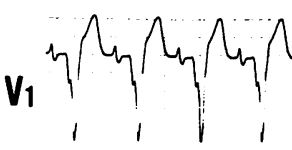

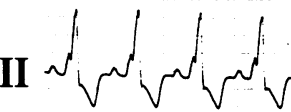

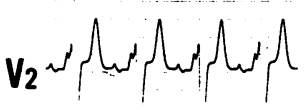

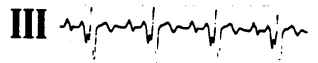

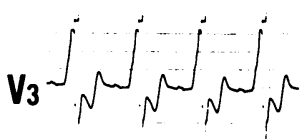<smiles>CCC(I)CC(I)CC(I)CC(I)CC(I)C(I)I</smiles>

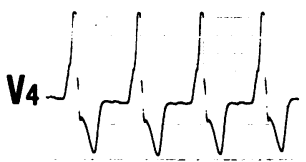

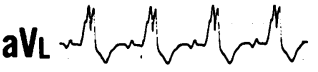

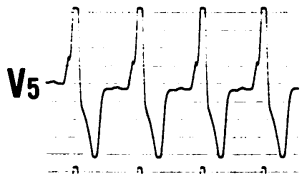

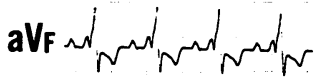

(A)

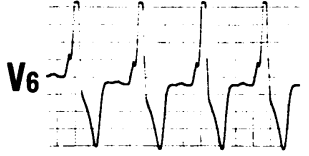
intraventricular conduction distrubance were found. interval is a common electrocardiographic finding in Fabry's disease. ${ }^{5}$ A few cases with complete atrioventricular block have been reported ${ }^{67}$ but pathological studies of the conduction system were lacking. We report the necropsy findings in a patient with Fabry's disease associated with complete atrioventricular block.

\section{Case report}

A 63 year old man was admitted to Mitsui Memorial Hospital with dyspnoea on 2 February 1988. Two years before complete left bundle branch block and left axis deviation were diagnosed at another hospital (fig 1A). The PR interval was $0 \cdot 16 \mathrm{~s}$ at that time. The day before admission he consulted a local doctor and the electrocardiogram showed complete atrioventricular block. The next day he was admitted to our hospital for investigation and treatment.

He had no history of painful paresthesia of the extremities, and no history of heat stroke during military training. An evaluation of his family history showed that four male cousins

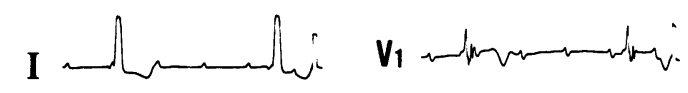<smiles>CC(C)CCCCCCCC(C)C</smiles><smiles>CCCCCCC(C)C</smiles><smiles>CCCC(C)C</smiles>

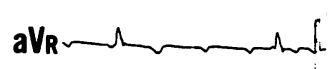<smiles>CCCCC(C)C</smiles>

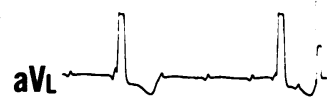

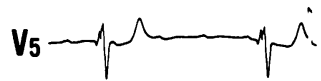

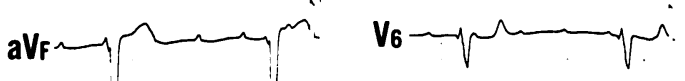

(B)

Figure 1 (A) An electrocardiogram taken two years before admission showed complete left bundle branch block, lef axis deviation, and a normal PR interval (0.16 s). (B) On admission complete atrioventricular block and 
Figure 2 (A) Light micrograph showing diffuse vacuolar degeneration in the bundle of His (left) and adjacent myocardium (right) (elastic van Gieson Stain, original magnification $\times 200$ ). (B) Electron micrograph showing that the

hypertrophic myocardial cells contained concentric lamellar bodies (lead citrate and uranyl nitrate stain, original

magnification $\times 130000$ ).
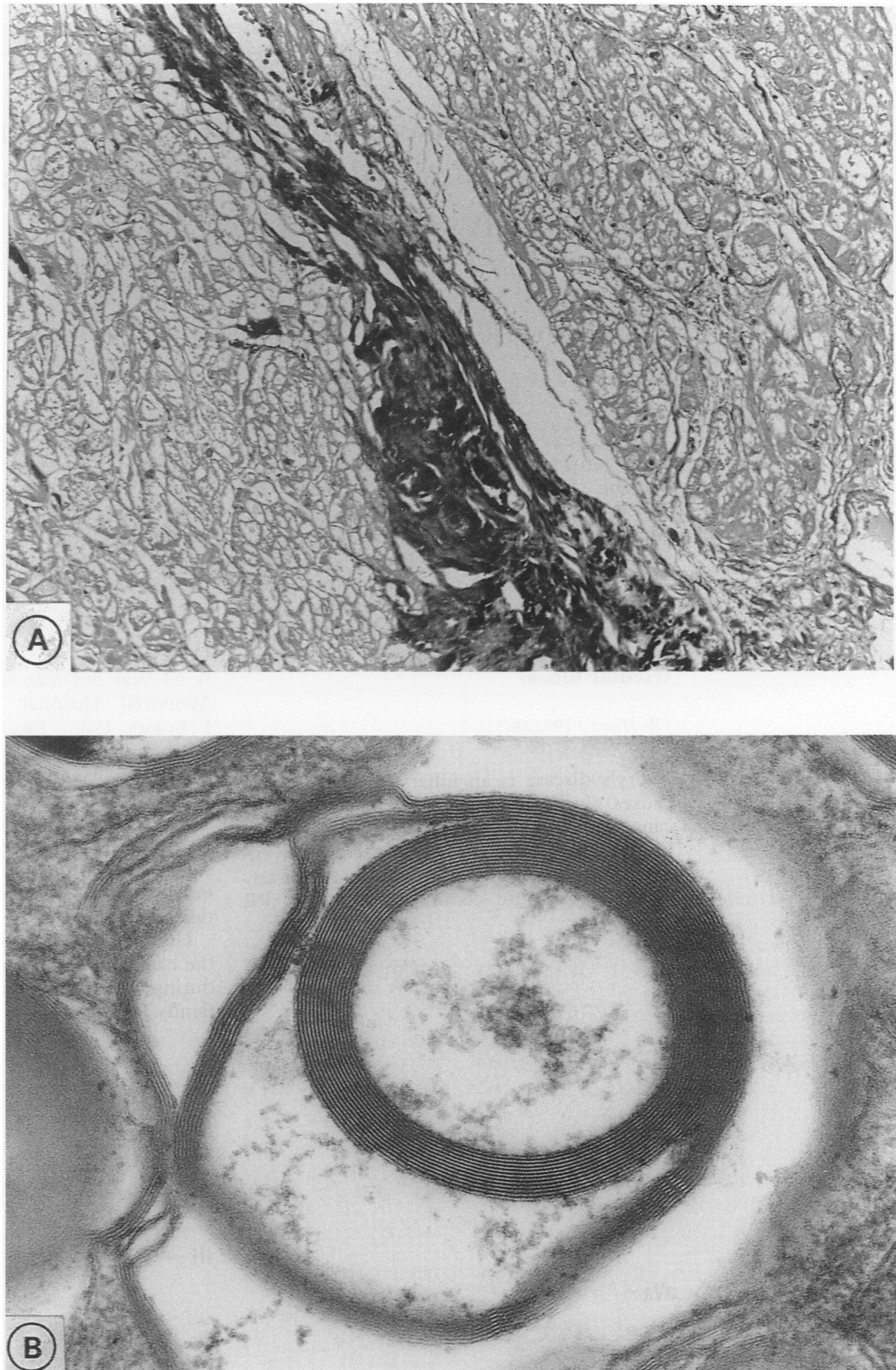

had died suddenly but no female relative had had cardiac disease.

On admission the pulse rate was 37 beats/ min and regular and the blood pressure was $130 / 60 \mathrm{~mm} \mathrm{Hg}$. Inspiratory rales were audible at both lung bases and a third heart sound was heard at the apex. There was no oedema of the extremities. Cutaneous angiokeratomas similar to senile angiomas were seen. No cataracts were found.
The heart was enlarged (cardiothoracic ratio $67 \%$ on a chest $x$ ray). The electrocardiogram showed complete atrioventricular block, left axis deviation, and intraventricular conduction defects (fig 1B). Laboratory studies indicated chronic renal failure and mild glucose intolerance. Blood urea nitrogen was $23.6 \mathrm{mmol} / \mathrm{l}$, creatinine was $336 \mu \mathrm{mol} / 1$, fasting plasma glucose was $10 \cdot 1 \mathrm{mmol} / \mathrm{l}$, and haemoglobin $A_{l c}$ was $6.3 \%$.

$$
\text { 응 }
$$


The echocardiogram showed left ventricular hypertrophy, left ventricular dilatation, and granular sparkling in the interventricular septum. Cardiac catheterisation and endomyocardial biopsy were performed, but coronary angiography was not done because of renal failure.

The mean pulmonary capillary wedge pressure was $23 \mathrm{~mm} \mathrm{Hg}$, the main pulmonary artery pressure was $59 / 20$ (mean 30 ) $\mathrm{mm} \mathrm{Hg}$, the right ventricular pressure was $50 /$ (end diastolic) $20 \mathrm{~mm} \mathrm{Hg}$, the mean right atrial pressure was $12 \mathrm{~mm} \mathrm{Hg}$, the left ventricular pressure was $165 /$ (end diastolic) $45 \mathrm{~mm} \mathrm{Hg}$, and the aortic pressure was $170 / 65 \mathrm{~mm} \mathrm{Hg}$. Cardiac output was $4.6 \mathrm{l} / \mathrm{min}$; and the cardiac index was $2 \cdot 8 \mathrm{l} / \mathrm{min} / \mathrm{m}^{2}$. It was impossible to record the bundle of $\mathrm{His}$ electrocardiogram, presumably because the bundle voltage was too low.

In an endomyocardial biopsy specimen there was extensive deposition of osmophilic concentric lamellar bodies in the lysosomes. These lamellar bodies had a myelin-like configuration and represented the accumulation of glycosphingolipids. Biochemical studies showed that $\alpha$-galactosidase $A$ activity was appreciably decreased, though the activities of other lysosomal enzymes were normal. The diagnosis of Fabry's disease was thus confirmed. He improved after the implantation of a permanent pacemaker (Activitrax 8400, Medtronic, Minneapolis, MN 55432, USA) and the administration of oral frusemide.

A year and nine months later he was admitted again because of worsening heart failure and renal failure. Dobutamine, dopamine, and frusemide were administered, but he died of heart failure on 7 February 1990.

At necropsy biventricular hypertrophy $(920 \mathrm{~g} / 52 \mathrm{~kg})$ and dilatation were found, but there was no evidence of myocardial infarction. Histological study showed severe diffuse vacuolar degeneration in the bundle of $\mathrm{His}$, the branches of the bundle of His, and the ventricular myocardium, while degeneration of the sinoatrial node was relatively mild (fig 2). Moderate vacuolar degeneration and foamy macrophage infiltration of the renal glomerular epithelium were also seen.

\section{Discussion}

Cardiac involvement in Fabry's disease occurs by the progressive deposition of glycolipids, mainly ceramide trihexoside, in the myocardial cells. Left ventricular enlargement and supraventricular arrhythmias are quite common findings. ${ }^{2-4}$

A short PR interval in Fabry's disease has been described before. Roudebush et al reported three brothers with Fabry's disease and a short PR interval, and their review of 120 reported cases suggested that a short PR interval was a common finding.' In the electrophysiological study performed by Matsui et al the short PR interval was shown to be caused by a reduction in the $\mathrm{A}-\mathrm{H}$ time with a normal $\mathrm{H}-\mathrm{V}$ time. ${ }^{8}$ The necropsy study by Becker et al showed glycosphingolipid deposits in the cells of the sinus node, the atrioventricular node, the bundle of His, and the left and right bundle banches. ${ }^{2}$ They proposed that glycosphingolipid accumulation in the conduction system caused the short PR interval in this disease. Mehta et al reported that the PR interval was short in five out of 32 patients with Fabry's disease and prolonged in three of 13 patients on follow up examination. ${ }^{6}$ They suggested that the prolongation was a result of progression of the disease process.

Complete atrioventricular block is rare in patients with Fabry's disease and only a few cases have been reported. ${ }^{67}$ An electrophysiological study of two brothers performed by Suzuki et al indicated that one had a block within the bundle of His and the other had 2:1 atrioventricular block inthe atrioventricular node. ${ }^{7}$ However, the cause of the atrioventricular block in their patients was not determined by a pathological study. Necropsy in our patient showed considerable deposition of glycosphingolipids in the bundle of $\mathrm{His}$ and bundle branches and no other pathological changes, suggesting that glycosphingolipid accumulation was the cause of his complete atrioventricular block. Complete atrioventricular block may be a terminal complication of Fabry's disease, with many patients apparently dying of renal failure before this cardiac defect can develop. Renal dysfunction in our patient progressed slowly and he lived until he was 65 years old; this gave time for the atrioventricular block to become apparent. We thank Dr Hitoshi Sakuraba (Department of Clinical
Genetics of the Tokyo Metropolitan Institute of Medical Genetics of the Tokyo Metropolitan Institute of Medical
Science) for the enzyme assay, Dr Masao Nakahama and $\mathrm{Dr}$ Science) for the enzyme assay, Dr Masao Nakahama and Dr
Riichiro Takanashi for the pathological diagnosis, and Mr Ieharu Yamazaki for providing the electron photomicrographs.

1 Densick RJ, Bishop DF. Fabry's disease: $\alpha$-galactosidase A deficiency. In: Scriver CR, Beaudet AL, Sly WS, Valle D, eds. The metabolic basis of inherited disease. 6 th ed. New York: McGraw-Hill, 1989:1751-80.

2 Becker A, Schoorl FR, Balk A, Heide RM. Cardiac manifestations of Fabry's disease. Am J Cardiol 1975;36:829-35.

3 Desnick R, Bielden L, Sharp H, Hofschire P, Moller J. Cardiac valvular anomalies in Fabry's disease-clinical, morphologic, and biochemical studies. Circulation morphologic, and

4 Sakuraba H, Yanagawa Y, Igarashi T, et al. Cardiovascular manifestations in Fabry's disease. Clin Genet 1986;29: 276-83.

5 Roudebush C, Foerster J, Bing $O$. The abbreviated PR interval of Fabry's disease. N Engl J Med 1973;289:357-8.

6 Mehta J, Tuna N, Moller JH, Densick RJ. Electrocardiographic and vectorcardiographic abnormalities in Fabry's disease. Am Heart J 1977;93:699-705.

7 Suzuki M, Goto T, Kato R, Yamauchi K, Hayashi H. Combined atrioventricular block and sinus node dysfunction in Fabry's disease. Am Heart J 1990;120:438-40

8 Matsui S, Murakami E, Takekoshi N, et al. Cardiac manifestations of Fabry's disease: Report of a case with pulmonary regurgitation diagnosed on the basis of endomyocardial biopsy findings. Jpn Circ J 1977;41:1023-36. 